\title{
The impact of ICT on service trade*
}

\author{
Tuan Anh Luong ${ }^{a}$ and Thu Hang Nguyen ${ }^{b \dagger}$ \\ ${ }^{\mathrm{a}}$ De Montfort University ${ }^{\mathrm{b}}$ Foreign Trade University
}

May 9, 2020

\begin{abstract}
While trade in goods has been investigated extensively over decades, studies on trade in services are relatively new. In this paper we investigate the impacts of information and communication technology (ICT) on trade in services. We measured ICT by four dimensions, including the subscriptions to broadband, fixed telephones, mobile phones and Internet. Our sample covered more than 200 countries, from 2005 to 2015. We employed the modified gravity model and found that all four dimensions had significant impacts on the expansion trade in services, but mobile subscriptions is the most consistent dimension. Finally the effects of ICT in exporting and importing countries are similar.
\end{abstract}

JEL classification: D12; F14; L66

Keywords: Information and Communication Technology; Service trade

${ }^{*}$ All opinions expressed in this paper are those of the authors and do not reflect the views of any organizations the authors are affiliated with. All remaining errors are our own.

${ }^{\dagger}$ Corresponding author: Foreign Trade University, 91 Chua Lang Street, Dong Da District Hanoi Vietnam. Email: nguyen.thuhang@ftu.edu.vn 


\section{Introduction}

International trade has been one of the main drivers of global economic growth. As the structure of international trade has been continuously evolving, trade in services now plays an important role. Its share of global GDP rose from $6 \%$ in 1960 to $13 \%$ in 2017. ${ }^{1}$ Besides, Gervais and Jensen (2019)suggest that potential welfare gains from trade liberalization in the services sector are large. The growing importance of trade in services prompted our effort to better understand the drivers behind this surge.

There are several possible factors to explain the rise of trade in services such as time zone (Christen 2017) or geography (Anderson et al. 2014). In this paper, we focus on perhaps the most important one: the advance of technology. More precisely, we look at the impact of information and communications technology (ICT) have an impact on communication and business costs which are crucial in services trade (Fink and Neagu 2005). ICT refers to technologies that provide access to information through telecommunications. It is similar to Information Technology (IT), but focuses primarily on communication technologies. It includes the Internet, wireless networks, cell phones, and other communications media.

The rapid development of ICT has transformed the world into a digital economy era, bringing significant benefits (WorldBank 2016). There is an ample evidence in the literature that shows the development of ICT has continuously reduced communication and trade costs. For instance, ICT decreases the cost of doing business as it helps to overcome the constraints of distance and boundaries in global markets (Spanos et al. 2002; Hanna 2010; Nath and Liu 2013; Lin 2014). At the same time, employing ICT can facilitate communication and give firms access to markets for innovative quality products, product promotion, online selling, networking at lower transactional costs (Kiveu 2013). Moreover, a strong ICT infrastructure enables data sharing across functions and divisions, which supports cross-functional decision-making and allows companies to communicate

\footnotetext{
${ }^{1}$ https://data.worldbank.org/indicator/bg.gsr.nfsv.gd.zs?end=2017\&start=1960\&view=chart
} 
and act more globally. In addition, it provides a base for faster development of business applications due to standardized platforms and common applications (Brown and Ross 1996). Accordingly, ICT development has changed how people and enterprises work and do business globally. Recently trends to communicate more and exchange information via the many applications of ICT have accelerated. As a result, the rise of ICT allows people and enterprises to transact and communicate more globally at lower costs.

There is an emerging literature examining the impact of ICT on trade in services. Internet development clearly could facilitate exports of services. Choi (2010) showed that doubling the Internet usage in a nation results in a $2 \%$ to $4 \%$ increase in value of services trade. Internet development in both the Home country and in its trading partners, could play a crucial role in the growth of services trade. Using detailed data on Other Private Services from 31 countries and 14 industries from 1995 to 1999, Freund and Weinhold (2002) showed that a $10 \%$ increase in the Internet penetration of the U.S trade partner led to a $1.7 \%$ growth in services trade. The role of Internet development is not limited to Internet usage. Wang and $\mathrm{Li}$ (2017) found that other indexes of Internet development such as broadband subscription, the use and skill of ICT also had significant impacts.

In this paper, we contribute to this literature by making use of the most recent and comprehensive datasets to answer two important questions. First, by having a comprehensive list of ICT indexes, we are able to evaluate the impact of the many dimensions of ICT. In this aspect, our paper is similar to Nath and Li (2017). However, instead of using the reduced-form regression employed i in those papers, we employ a structural model derived from the famous gravity equation. In addition, our analysis covers a wider range of countries (228 countries compared to 49 countries in Nath and Li (2017). Second, different from previous papers, we aim to assess the impact of ICT from both the importer and exporter perspective. In other words, our paper combines the findings of Freund and Weinhold (2002) and Choi (2010) in a comprehensive analysis.

The paper is organized as follows. In Section 3, we describe our data. We 
then explain our empirical strategy in Section 4. We report our results in Section 5 and make concluding remarks in Section 6.

\section{Theoretical model}

\subsection{Demand}

We assume that consumers worldwide have identical and homothetic preferences. More particular, the preferences of consumers in country $\mathrm{j}$ follow the constant elasticity of substitution (CES) utility function as follows:

$$
U_{j}=\left(\sum_{i} \alpha_{i}^{\frac{1-\sigma}{\sigma}} c_{i j}^{\frac{\sigma-1}{\sigma}}\right)^{\frac{\sigma}{\sigma-1}}
$$

In the above equation, $\sigma>1$ is the elasticity of substitution among different varieties. In our model, the variety is defined by the country of origin. The elasticity of substitution captures the similarity of varieties: high $\sigma$ means the varieties are very similar. The parameter $\alpha_{i}$ is the taste parameter: the consumers prefer goods from countries with high $\alpha$. Finally, $c_{i j}$ is the quantity of goods imported from country i to country j.

If consumers in country $\mathrm{j}$ have a fixed budget $E_{j}$ then they will buy goods subject to the budget constraint:

$$
\sum_{i} p_{i j} c_{i j}=E_{j}
$$

In the above equation, $p_{i j}$ is the price that consumers in country $\mathrm{j}$ pay when buying from country i. This price is the sum of the factory-gate price $c_{i}$ and the trade costs $\tau_{i j}$ between the two countries:

$$
p_{i j}=c_{j} * \tau_{i j}
$$

We will discuss the trade $\operatorname{costs} \tau_{i j}$ in the next section. When we solve for 
the consumer's optimization problem (Equations 1 and 2) we have the values of goods shipped from country i to country $\mathrm{j}$ as:

$$
X_{i j}=\left(\frac{\alpha_{i} p_{i j}}{P_{j}}\right)^{1-\sigma} E_{j}
$$

The variable $P_{j}$ is the consumer price index in country j:

$$
P_{j}=\left(\sum_{i}\left(\alpha_{i} p_{i j}\right)^{1-\sigma}\right)^{\frac{1}{1-\sigma}}
$$

\subsection{Supply}

We impose the market clearing condition, that is the value of output in country i must equal the total expenditures on goods of this country all over the world:

$$
Y_{i}=\sum_{j} X_{i j}
$$

If we define world output $Y=\sum_{i} Y_{i}$ then we can rewrite (6) as:

$$
\left(\alpha_{i} c_{i}\right)^{1-\sigma}=\frac{Y_{i} / Y}{\Pi_{i}^{1-\sigma}}
$$

In the above equation, $\Pi$ is the multilateral resistance (Anderson and van Wincoop (2003)), defined as:

$$
\Pi_{i}=\left(\sum_{j}\left(\frac{\tau_{i j}}{P_{j}}\right)^{1-\sigma} \frac{E_{j}}{Y}\right)^{\frac{1}{1-\sigma}}
$$

\section{$2.3 \quad$ Trade costs}

Now we can specify the trade $\operatorname{costs} \tau_{i j}$. The traditional formula for the timevariant trade costs can be written as: 
$(1-\sigma) \tau_{i j, t}=\beta_{1} \operatorname{lnDIST} T_{i j}+\beta_{2} C N T G_{i j}+\beta_{3} L A N G_{i j}+\beta_{4} C L N Y_{i j}+\beta_{5} F T A_{i j, t}+\epsilon_{i j, t}$

in which the terms $D I S T_{i j}, C N T G_{i j}, L A N G_{i j}, C L N Y_{i j}$, denote the bilateral distance and whether the countries share the border, have the same language and colonial ties. The term $F T A_{i j, t}$ takes the value 1 if the two countries have a free trade agreement at time $t$. The error $\epsilon_{i j, t}$ denotes any other factors that affect the trade costs (such as bilateral tariffs). In the case of service trade, we assume that the trade costs can take the form of communication costs which depend on the level of ICT of both the source and the destination countries:

$$
\begin{aligned}
(1-\sigma) \ln \tau_{i j, t}=\beta_{1} \ln D I S T_{i j}+\beta_{2} C N T G_{i j}+\beta_{3} L A N G_{i j} & +\beta_{4} C L N Y_{i j}+\beta_{5} F T A_{i j, t}+ \\
& +\beta_{6} I C T_{i t}+\beta_{7} I C T_{j t}+\epsilon_{i j, t}
\end{aligned}
$$

\subsection{The gravity equation}

If we replace $\alpha_{i} p_{i j}$ in Equation (4) by Equations (3), (7) and (9) and take the natural logarithmic we will have the gravity equation written in log terms:

$$
\ln X_{i j, t}=(1-\sigma) \beta_{6} I C T_{i t}+(1-\sigma) \beta_{7} I C T_{j t}+(1-\sigma) \beta_{8} I_{i t}+(1-\sigma) \beta_{9} I_{j t}+F_{j t}+F_{i t}+F_{t}+\epsilon_{i j t}
$$

where $F_{j t}=\ln E_{j t}-(1-\sigma) \ln P_{j t}, F_{i t}=-(1-\sigma) \ln \Pi_{j t}$ and $F_{t}=-\ln Y_{t}$. In order to employ the fixed effects to control for the unobservable variables $F_{j t}, F_{i t}$ we will rewrite the above Equation as follows: 
$\ln X_{i j, t}=(1-\sigma) \beta_{6} I C T_{i t}+(1-\sigma) \beta_{7} I C T_{j t}+(1-\sigma) \beta_{8} I_{i t}+(1-\sigma) \beta_{9} I_{j t}+F_{j}+F_{i}+F_{t}+\epsilon_{i j t}$

The Equation (11) is the main specification of our model. As high level of ICT potentially reduces the trade costs, we expect $\beta_{6}$ and $\beta_{7}$ to be significantly negative. Given that $1<\sigma$, the coefficients of $I C T_{i t}$ and $I C T_{j t}$ are expected to be positive.

\section{Data}

To measure ICT across countries and years, we use data from the International Telecommunication Unions (www.itu.int) on the subscriptions of broad band, fixed telephone and mobile cellular. The data reported the number of subscriptions of these ICT dimensions in 228 countries from 2005 to 2015. In order to compare to previous studies which mostly focused on the impact of Internet on service trade, we also use the percentage of Internet users in these countries. We also use the value of service trade reported by the World Trade Organization (WTO). This data is the estimate based on the Eurostat estimates. It covers different categories of trade in services such as transportation (Air, Sea, Rail, etc.), Insurance (Life, Goods, etc.), Financial services, Electricity transmission, Postal service, etc.

In addition to the two main datasets mentioned above, we also employ the gravity dataset from le Centre des etudes prospectives et dinformations internationales (CEPII). Furthermore we collect data on the submarine Cable from TeleGeography. They report on all the major transnational cable networks. Arguably the existence of the cable networks reduces the digital distance between countries.

The summary statistics of key variables are provided in Table 1. In particular about one fourth of the people had broadband, although the proportion of people who had access to Internet was two-thirds. Although one person might have had 
more than 1 cell phone, it is fair to say that the statistics suggested that the majority of people had cell phones.

[Insert Table 1 here]

\subsection{Trade values}

Figure 1 shows the total value of global trade in service. We can see that trade in service rose from 2005 until the financial crisis in 2009. After that it increased consistently until the trade collapse in 2016.

\subsection{Information and Communications Technology Dimensions}

One of the contributions of our paper is that we provided a comprehensive list of ICT dimensions. Table 2 shows that they are highly correlated. For instance, the correlation between broadband subscriptions and Internet user and xed telephone subscriptions is $87 \%$. It implies that all of these dimensions are important indexes of the ICT development.

[Insert Table 2 here]

Figure 2 and figure 3 describe the trend and rise of ICT development in all over the world in $2000-2017^{2}$. We used the financial crisis in 2009 to divide our sample into two periods: pre-crisis and post-crisis. In particular, Figure 2 reports the development of ICT across countries. Each point corresponds to the average of the ICT dimensions annually. As for broadband subscriptions: in 2005, the average subscription of broadband was around $13 \%$, it went up sharply in 2008, and then dropped in 2009 because of the global crisis. After that, it continued to increase consistently and reached to 30\% in 2017 (see Figure 2a). Similar experience applied to the percentage of Internet users. In 2005, there were $53 \%$ internet users across countries, except for the sharp decrease in 2009, the percentage of internet users was on the increasing trend over the time, and reach to $78 \%$ in 2017 (see Figure 2b). Mobile subscriptions rose tremendously in

\footnotetext{
${ }^{2}$ Although we have data of trade values and ICT up to 2017, the CEPII data is only available until 2015. As a result, our period of analysis will be 2005-2015.
} 
the pre-crisis period, from $80 \%$ to $120 \%$. The financial crisis in 2009 seemed to stop the momentum. Since 2009, these subscriptions stalled at 120\% (see Figure 2c). Since fixed telephones and mobile phones are substitutes, it was not a surprise to see the fixed telephone subscriptions mirrored those of mobile phones in the opposite direction. Indeed, the number of fixed telephone subscriptions dropped from almost 50\% in 2005 to $40 \%$ in 2008 before stabilized at $30 \%$ after the financial crisis (see Figure 2d). To summarize, the pre-crisis and post-crisis showed the consistent rise of ICT in the world.

Although the level of ICT on average surged as we saw in Figure 2, their impacts will be diminished if the bottom countries (i.e. countries with the lowest level of ICT) could not catch up with the top countries since ICT provides the means for the exporters and importers to communicate. In Figure 3 we showed the gaps between the top countries and the bottom countries significantly reduced. In each sub figure, we plotted the 90th percentile and 10 percentile of subscriptions for each ICT dimensions. We can see that the gaps in broadband subscriptions between these two groups dropped from $25 \%$ in 2005 to $18 \%$ in 2017 (see Figure 3a). More impressively was the results for Internet users and mobile phone subscriptions, where the gaps dropped by $20 \%$ and $30 \%$ respectively (see Figures $3 \mathrm{~b}$ and $3 \mathrm{c})$. As for fixed telephone subscriptions, the gaps between the top and the bottom countries seemed to be unchanged (see Figure 3d).

\section{Specifications}

\subsection{Benchmark model}

In the first specification, we will employ the simplest form of the gravity Equation (11) that we derive in Section 2. In particular we only consider ICT as the only distance between countries. In other words, we impose the conditions that $\beta_{8}=\beta_{9}=0$ and $F_{i}=F_{j}=0$. As a result, we have the first specification:

$$
\log (\text { Service-trade })_{i j s t}=\beta_{0}+\beta_{1} * \log (I C T)_{i t}+\beta_{2} * \log (I C T)_{j t}+I_{t}+I_{s}+u_{i j s t}
$$


In this specification 12, Service - trade $e_{i j k t}$ is the value of service trade in sector $s$ from country $i$ to country $j$. The independent variables $I C T_{i t}$ are the dimensions of ICT in country $i$, i.e. the subscriptions of broadband, fixed telephones, mobile phones and the percentage of Internet users. The time fixed effect $I_{t}$ is included to control for any development that is only time-specific, for instance, the rise of trade in service in general. Moreover, as our analysis in Section 2 is sector specific, we need to control for the sector fixed effect $I_{s}$.

\subsection{Gravity model}

In the previous specification, we impose the condition that $\beta_{8}=\beta_{9}=0$. In other words, we implicitly assume that other gravity variables do not have significant impacts on the volume of trade, especially in service trade. This is a strong assumption. For instance, as shown in Equation 4, larger countries will have larger expenditures on service trade. To control for the size of countries, we add the population and GDP per capita of each country in the second specification. Countries will engage in more trading activities if they have common languages, currency, and legal system. In addition, business will be facilitated if the cost of setting business is lowered. Finally, there is evidence that geography (Anderson et al. 2014) and time-zone (Christen 2017) matter for service trade. All of these variables are included in the following specification:

$$
\begin{aligned}
\log (\text { Service }- \text { trade })_{i j s t}= & \beta_{0}+\beta_{1} * \log (I C T)_{i t}+\beta_{2} * \log (I C T)_{j t}+\beta_{3} * I_{i t} \\
& +\beta_{4} * I_{j t}++\beta_{5} I_{i j} I_{t}+I_{s}+u_{i j s t}
\end{aligned}
$$

In this specification, $I_{i t}, I_{j t}$ and $I_{i j}$ denote the gravity variables that we mention above.

\subsection{Country-pair fixed effects}

In the previous specifications, we simplify our gravity equation 11 by assuming that $F_{i}=F_{j}=0$. In this specification we will relax this assumption. There are two purposes of this relaxation. First, it brings us to the full gravity equation 11. 
Second it will address the endogeneity issue. Indeed, the independent variables ICT can be endogeneously determined. For instance, ICT development can be a timely trend: Internet and mobile phones have become much more affordable than before. Meanwhile, some countries might have policies that promote the development ICT. The fixed effects that we have in the previous specifications can address these issues. In particular, the time fixed effect will pick up any time trend that might affect the development of ICT. In this specification, we add the country-pair fixed effect to pick up any country or country-pair policies that have an effect on ICT. Our final specification will be the following:

$$
\begin{aligned}
\log (\text { Service }- \text { trade })_{i j t}= & \beta_{0}+\beta_{1} * \log (I C T)_{i t}+\beta_{2} * \log (I C T)_{j t}+\beta_{3} * G D P_{i t} \\
& +\beta_{4} * G D P_{j t}+\beta_{5} * G D P C_{i t}+\beta_{6} * G D P C_{j t}+\beta_{7} * F D_{i t} \\
& +\beta_{8} * F D_{j t}+I_{t}+X_{i}+X_{j}+u_{i j t}
\end{aligned}
$$

Note that in all specifications we cluster the observation by the exporterimporter pair to reflect the fact that the unobserved components within the pair might be correlated.

\section{Results}

Table 3 reports the estimates of ICT elasticities of trade in service, as in 12. It shows that all dimensions from both importing and exporting countries have significant impact on the value of bilateral trade in service. In particular, a 10 percent increase in the broadband subscription resulted in an increase of 2 percent in the trade value. The impacts of fixed telephone subscriptions, mobile subscriptions and Internet users are even higher, being 3\%, $4 \%$ and $5 \%$ respectively.

[Insert Table 3 here]

Table 4 shows the impacts of the gravity variables. Columns $1,2,3$ and 4 
correspond to the regression where the independent variables are broadband subscription, Internet users, fixed telephone subscriptions and mobile phones. All of the impacts are in line with the literature. For instance, a $10 \%$ increase in the population (either in the exporting country or in the importing country) raised the value of service trade by $3 \%$. If these people were richer by $10 \%$, they would spend $4 \%$ more on service trade. A $10 \%$ increase in the geographical distance lowered service trade by $2.5 \%$. Time zone, however, had insignificant impact, possibly because unlike traditional trading activities service trade could take place anytime. Trade in service would prosper if the trade partners shared borders, language and the GATT/WTO memberships. An interesting feature is the impact of the cable connection. Table 4 shows that a cable network that connected two countries would increase the trade in service by $50 \%^{3}$.

[Insert Table 4 here]

However, our focus was on the impact of ICT. Table 5 shows that in the presence of other gravity variables, all of our ICT dimensions still have significant impacts on the volume of service trade. It is understandable that as we have more controls, the magnitude of the ICT effects is smaller. In particular, it dropped from up to $5 \%$ in Table 3 to $1 \%$ in Table 5 . Also interesting is that the impact of the ICT in the importing countries seemed to be less important relative to that in the exporting countries.

[Insert Table 5 here]

In Table 6 we included the country-pair fixed effect as in the full gravity equation 14. These fixed effect picked up all the variables that are ExporterImporter specific. Together with the time fixed effect, they controlled for the potential omitted variables that might result in the endogeneity issue. Results in Table 6 shows that now only the mobile subscription has significant impacts on service trade. While many papers in the literature focuses on the number

\footnotetext{
${ }^{3}$ We thank the anonymous referee for suggesting this point
} 
of Internet users as the proxy for the ICT development, this finding shows that mobile subscription has the most consistent impact.

\section{[Insert Table 6 here]}

In all of Tables $(3,5$ and 6$)$ we notice that the impacts of ICT dimensions in the exporting countries are of similar magnitude of those of the importing countries. It is consistent with the argument that the "digital distance" depend on the development of ICT of all the trading countries.

\section{Conclusion}

In this paper we studied the impacts of ICT dimensions, namely broadband, Internet, xed and mobile telephone on trade in services. We found significant impacts from all 4 dimensions. In particular, a 10\% increase in the subscriptions of these dimensions resulted in an increase of from $1 \%$ to $5 \%$ in the value of trade in services. As a result, investment on ICT would be the way forward to boost international trade and global economy. We also found that mobile subscription is the most consistent ICT dimension. Finally the effects from the exporting country and from the importing country were of similar magnitude, suggesting that all countries need to invest on ICT to boost services trade.

\section{References}

Anderson, J., C. Milot, And Y. Yotov (2014): "How much does geography deflect services trade? Canadian answers," International Economic Review, $55(3), 791-818$.

Anderson, J. And E. VAn Wincoop (2003): "Gravity with Gravitas: A Solution to the Border Puzzle," American Economic Review, 93(1), 170-192.

Brown, C. AND J. Ross (1996): "The Information Systems Balancing Act: Building Partnerships and Infrastructure," Information Technology \& People, $9(1), 49-62$.

Chor, C. (2010): "The impact of internet on service trade," Economics Letters, 109, 102-104.

Christen, E. (2017): "Time Zones Matter: The Impact of Distance and Time Zones on Services Trade," World Economy, 40(3), 612-631.

Fink, C., A. M. And C. Neagu (2005): "Assessing the impact of communi- 
cation costs on international trade," Journal of International Economics, 67, $428-445$.

Freund, C. And D. Weinhold (2002): "The Internet and International Trade in Services," American Economic Review, 92(2), 236-240.

Gervais, A. And B. Jensen (2019): "The tradability of services: Geographic concentration and trade costs," Journal of International Economics, 118, 331350 .

Hanna, S. (2010): "Call centres as sites of professional practice: Where do old social workers go to die?" Australian Social Work, 63(3), 266-280.

KIveu, M. (2013): "Enhancing market access in Kenyan SMEs using ICT," Global Business and Economics Research Journal, 2(9), 29-46.

Lin, F. Q. (2014): "Estimating the Effect of the Internet on International Trade," The Journal of International Trade E Economic Development, 24(3), 409-428.

NATH, H. AND L. Li (2017): "Information and communications technology (ICT) and services trade," Information Economics and Policy, 41, 81-87.

NATH, H. AND L. LiU (2013): "Information and Communications Technology (ICT) and Trade in Emerging Market Economies," Emerging Market Finance and Trade, 49(6), 67-87.

Spanos, Y., G. Prastacos, and A. Poulymenakou (2002): "The relationship between information and communication technologies adoption and management," Information and Management, 39, 659-675.

WANG, Y. AND J. Li (2017): "ICTs effect on trade: Perspective of comparative advantage," Economics Letters, 155, 96-99.

WorldBank (2016): "World Development Report 2016: Digital Dividends," .

\section{Tables}




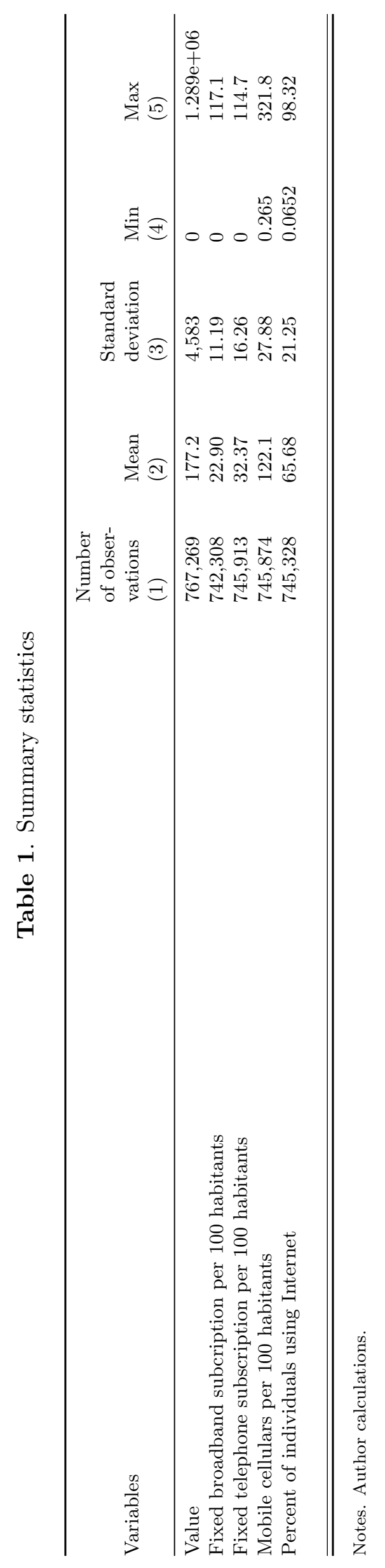




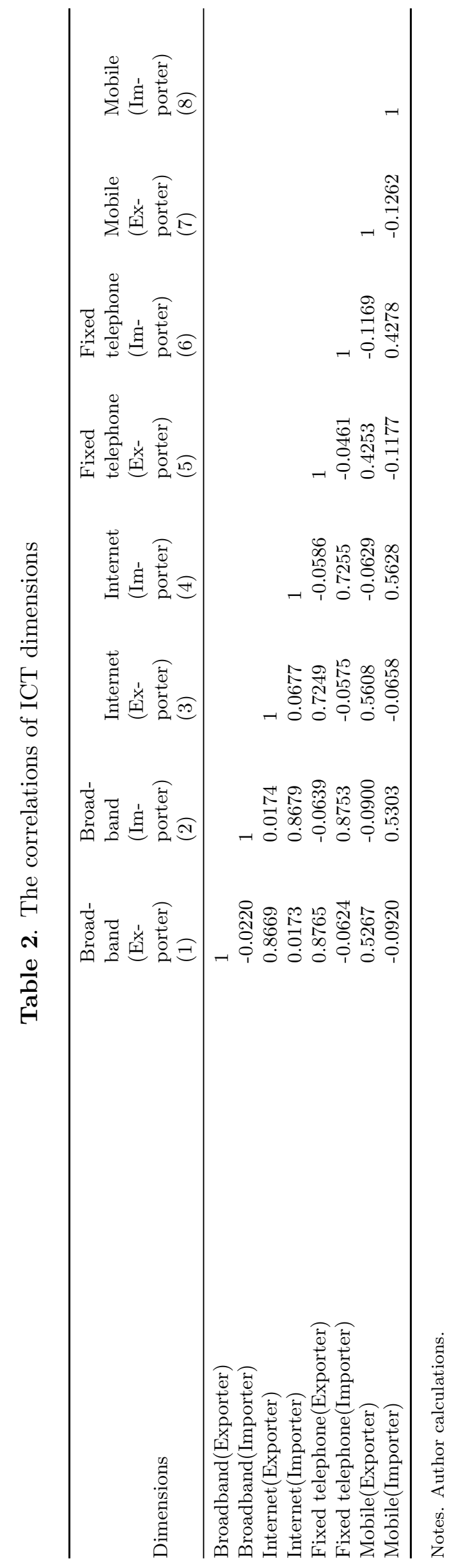




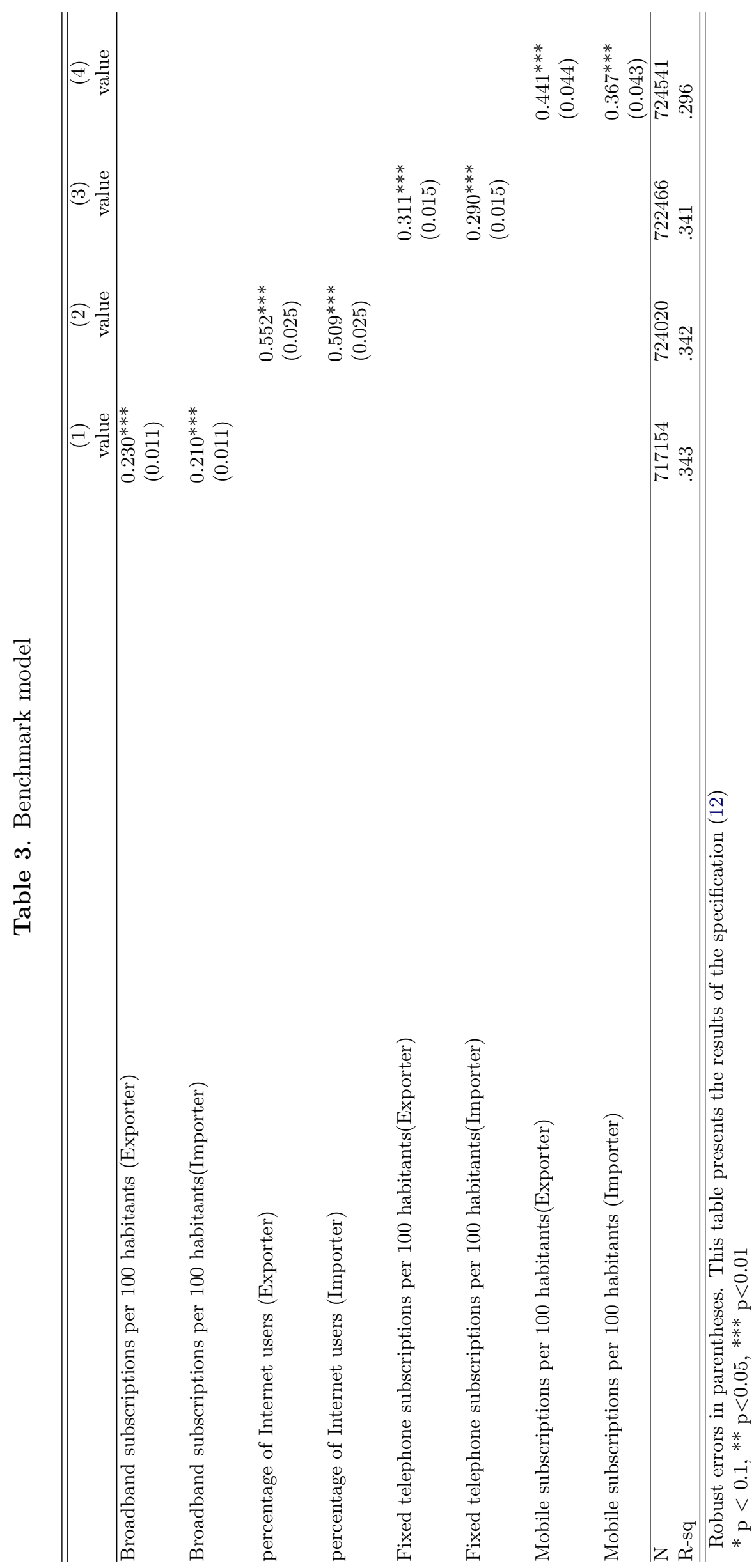




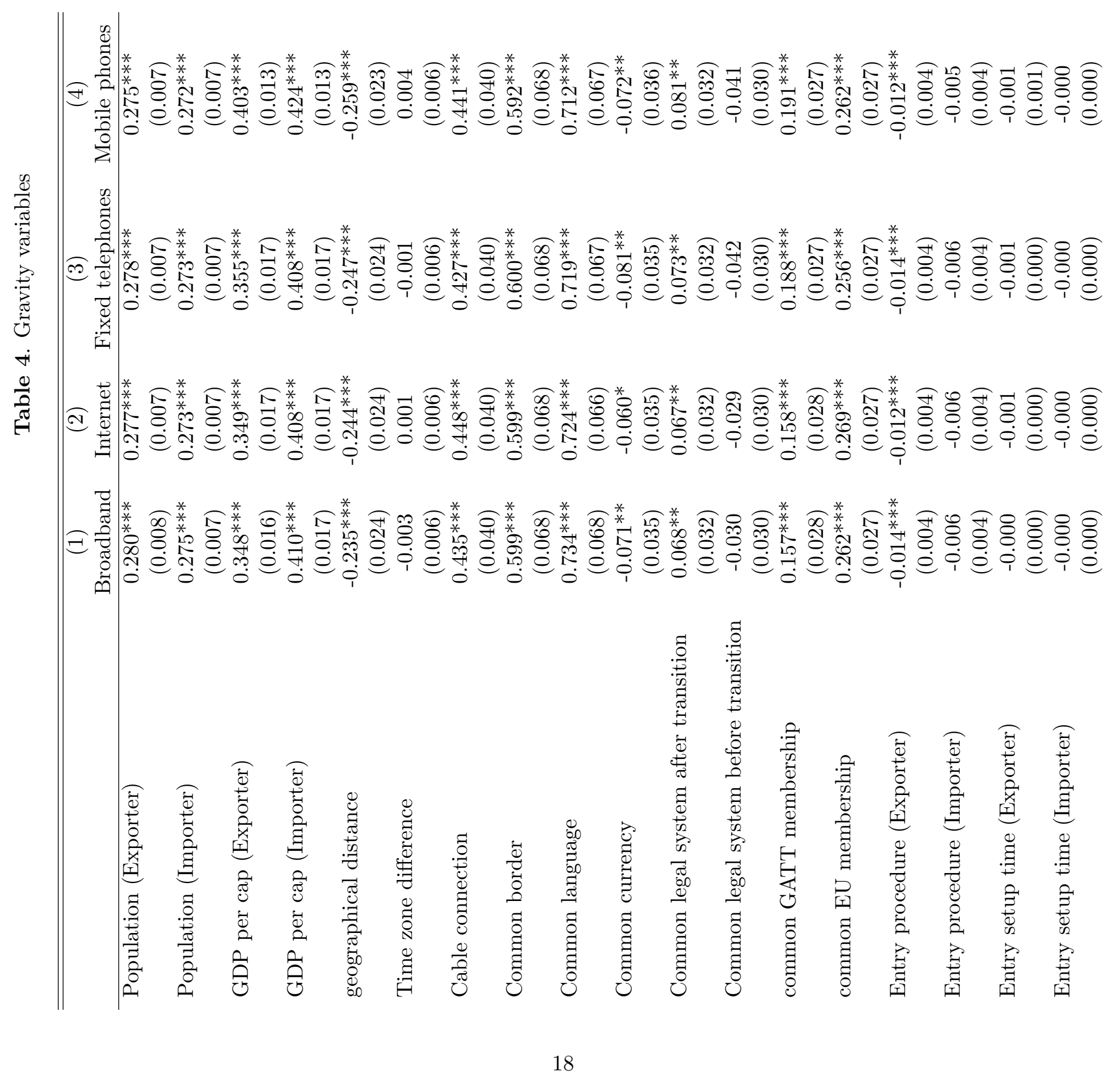




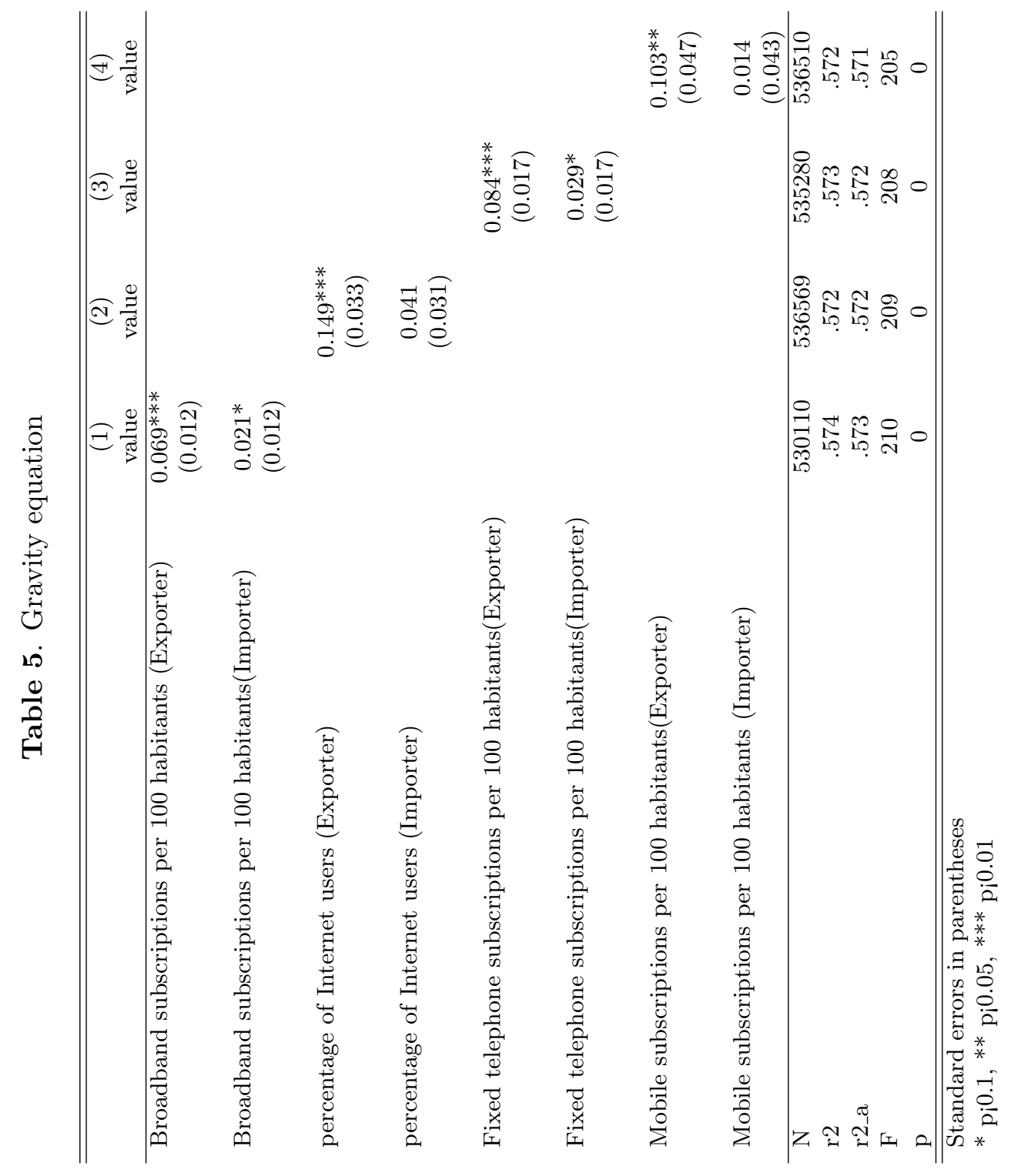




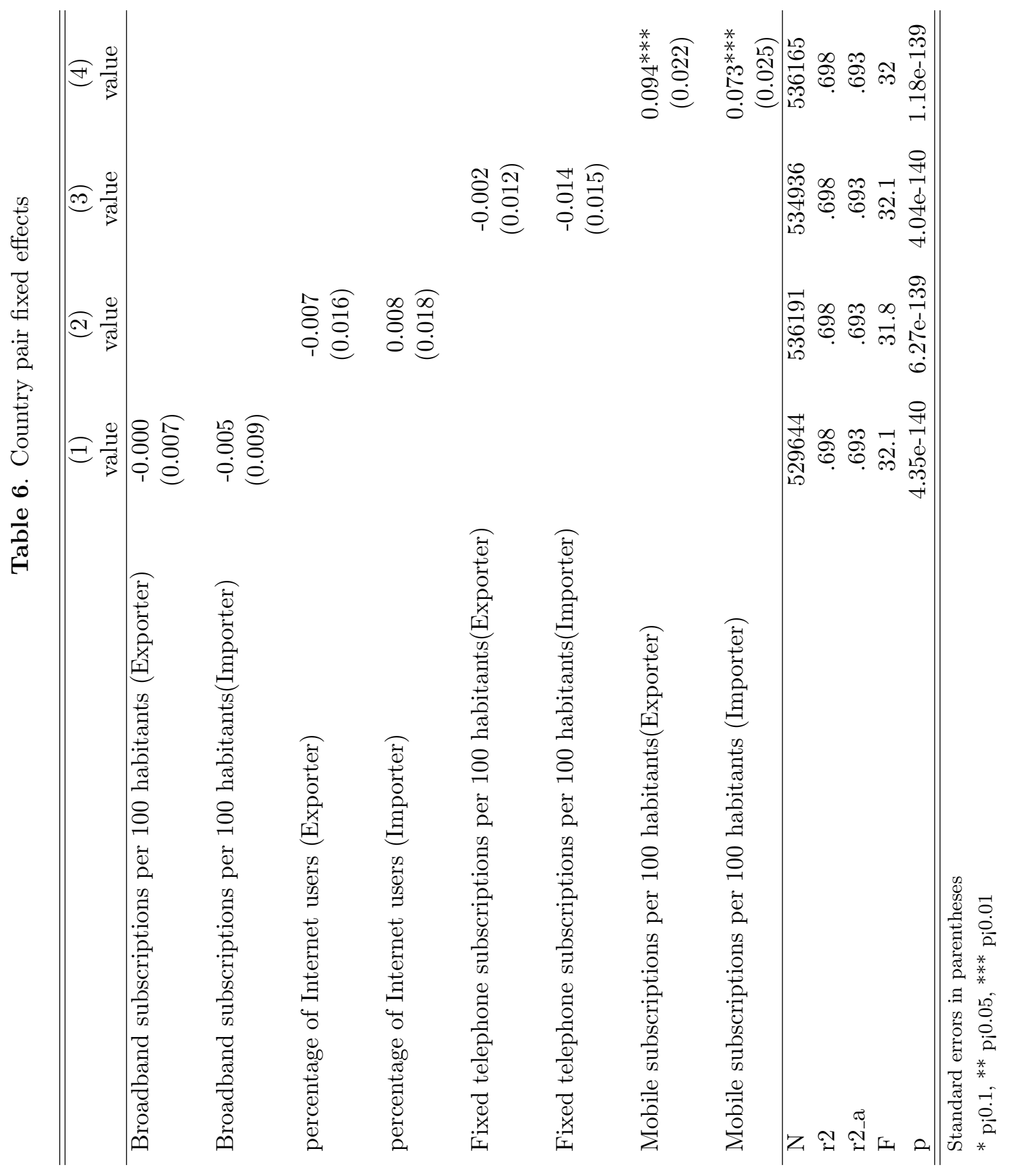


Figures 


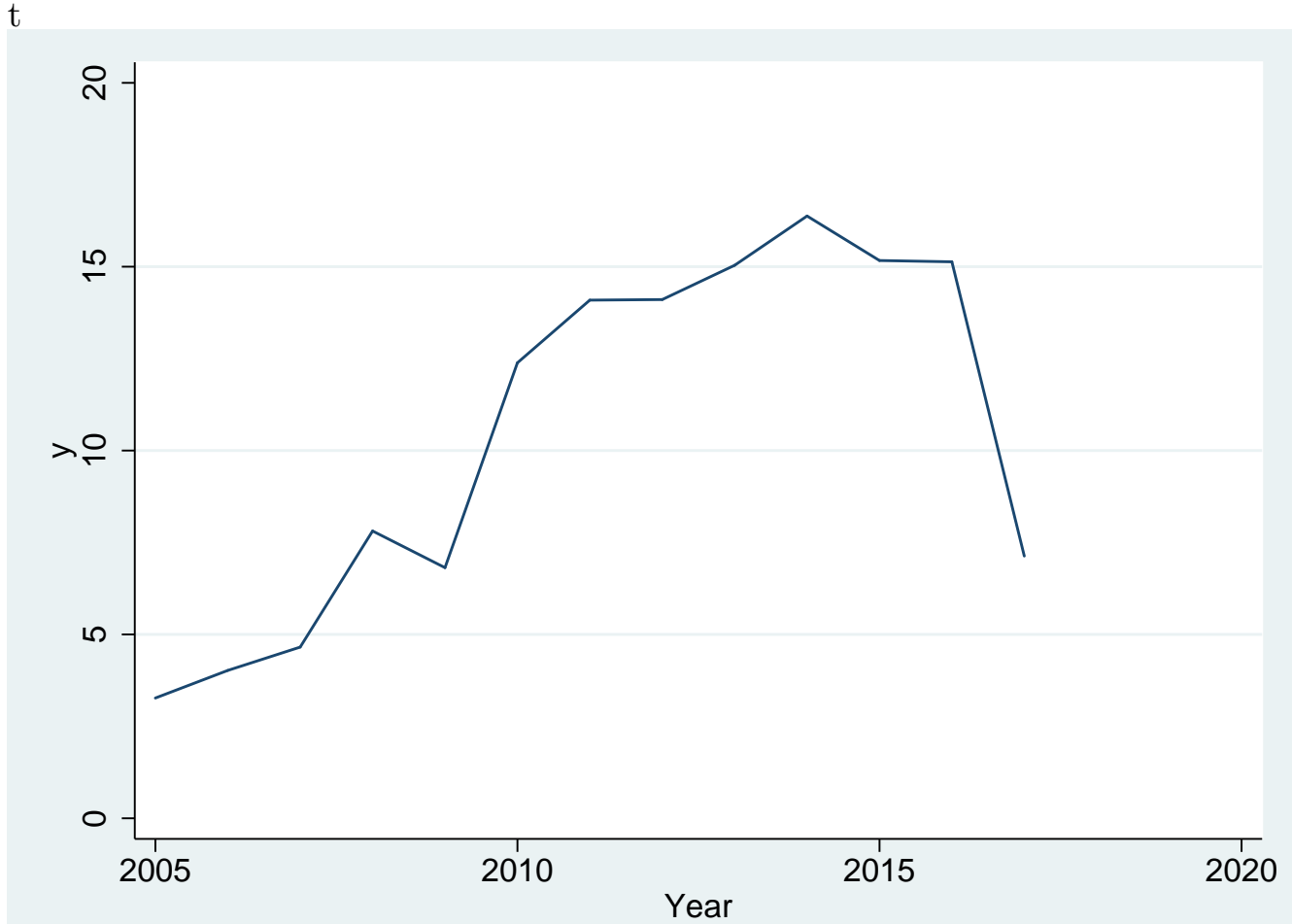

Figure 1. Global trade services in value (trillions USD) 


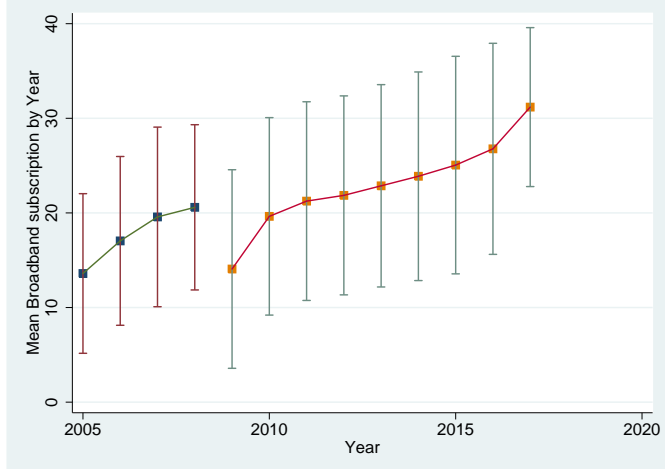

(a) Broadband subscriptions

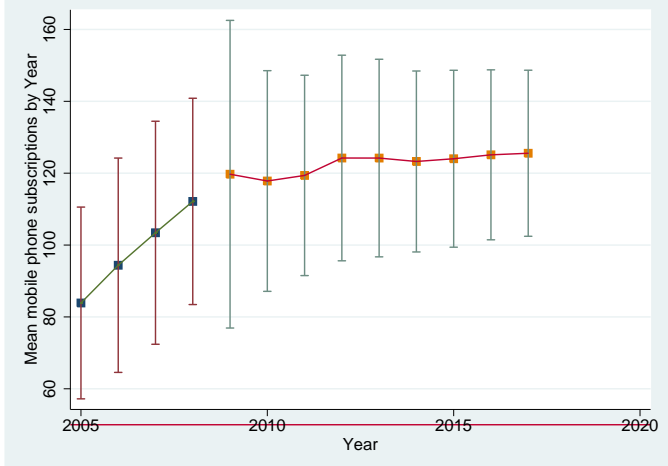

(c) Mobile phone subscriptions

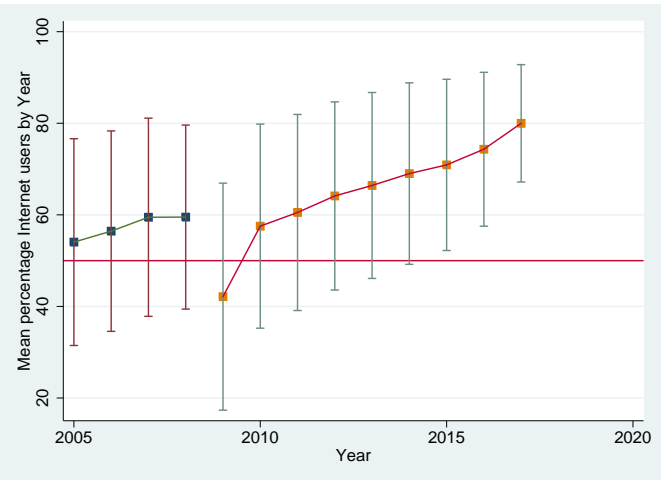

(b) Percentage of Internet users

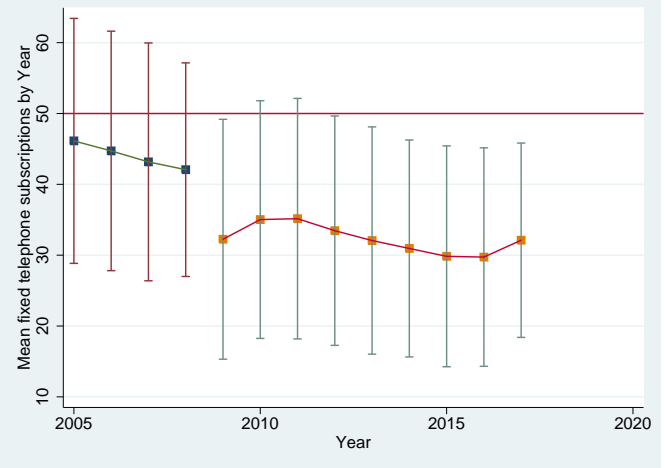

(d) Fixed telephone subscriptions

Figure 2. The rise of ICT. Source: Authors' calculation. 


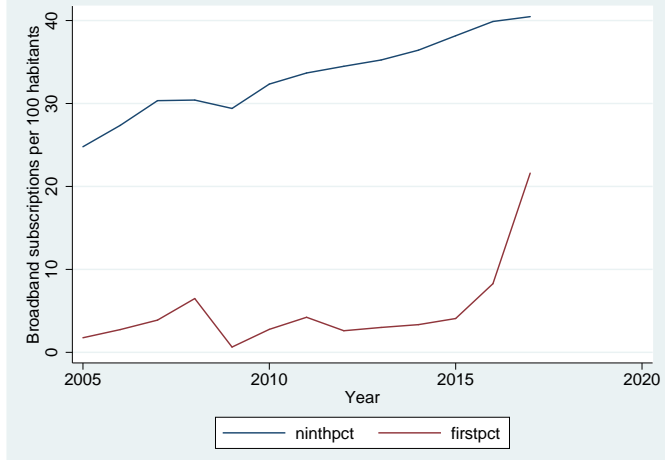

(a) The top and bottom of broadband subscriptions

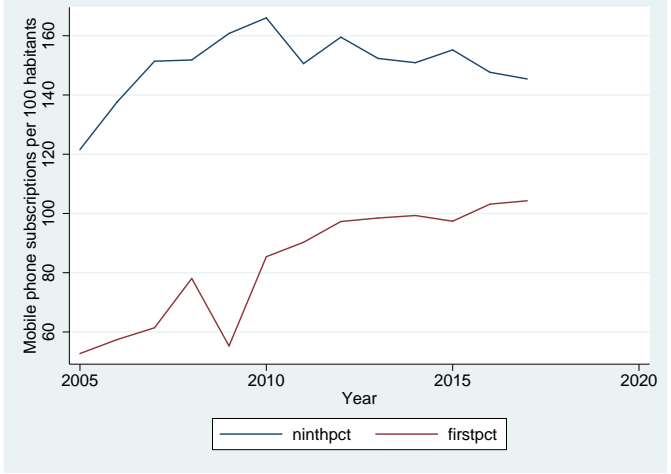

(c) The top and bottom of mobile phone subscriptions

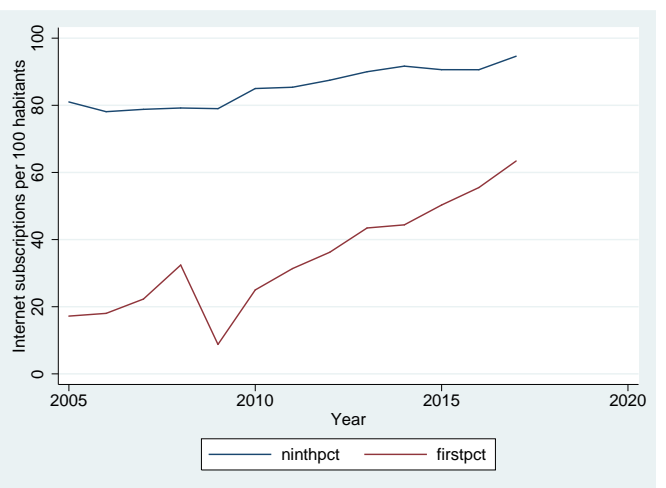

(b) The top and bottom of Internet users

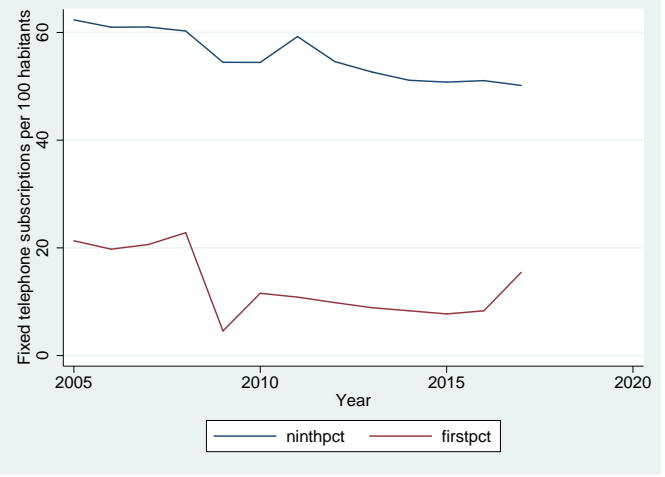

(d) The top and bottom of fixed telephone subscriptions

Figure 3. The catchup of ICT. The blue lines are the 90th percentile and the red lines are the 10th percentiles. Source: Authors' calculation. 